\title{
A Controvérsia do Capital de Hayek-Knight
}

\author{
Gabriel Oliva*
}

\begin{abstract}
Resumo: Este trabalho discute o debate sobre a teoria do capital entre Frank H. Knight e Friedrich A. Hayek ocorrida na década de 1930. Busca-se realizar uma reconstituição histórica dessa controvérsia entre Hayek e Knight, tentando entendê-la em seus próprios termos através da sumarização dos argumentos de ambos os participantes da mesma e situando cada artigo que a compõe no contexto dos desenvolvimentos teóricos correntes desses autores. Além disso, identifica-se a forma com que a teoria do capital de cada um dos autores é influenciada ou influencia as demais posições defendidas pelos mesmos em outros temas relacionados, em especial, o escopo e método da ciência econômica.
\end{abstract}

Palavras-chave: F. A. Hayek, Frank Knight, Teoria do Capital.

\section{The Capital Controversy of Hayek-Knight}

\begin{abstract}
This paper discusses the debate on capital theory between Frank H. Knight and Friedrich A. Hayek, which took place in the 1930s. The central objective is to make a historical reconstitution of this controversy, trying to understand it in its own terms by summarizing the arguments of both participants and placing each of its component articles in the context of the current theoretical developments of these authors. Furthermore, it is identified the way both capital theories are influenced or influence the other positions defended by the authors in related themes, especially, the scope and method of economic science.
\end{abstract}

Keywords: F. A. Hayek, Frank Knight, Capital Theory.

Classificação JEL: B31, B25.

\footnotetext{
* Gabriel Oliva possui graduação em Economia pela Universidade de São Paulo (2013), mestrado em Economia pela Universidade de São Paulo (2016) e atualmente é doutorando em Economia pela Universidade de Duke. Possui interesse nas áreas de História do Pensamento Econômico, Economia e Complexidade e Economia do Desenvolvimento.

E-mail: gabriel.cunha@duke.edu
} 
If there is any connection between reasoning and conclusions and if "correct" economic theory has any superiority of any kind over that which is incorrect, there can be no greater "service" to economic thought than that of striking any blow tending to

free it from the incubus of the generally accepted theory of capital in most of its aspects. Reference is made to the "wage fund" theory of the early classical writers as modified by Jevons, Böhm-Bawerk, and Wicksell, and disseminated chiefly by Böhm-Bawerk.

Frank H. Knight

\section{I - INTRODUÇÃO}

A questão de como a teoria econômica deveria tratar o capital é um tema de grande complexidade que gerou diversas controvérsias ao longo da história do pensamento econômico. Muita pesquisa e atenção já foram devotadas à compreensão da controvérsia do capital de Cambridge, a qual envolveu representantes diretos e indiretos da Cambridge britânica (Joan Robinson (1903-1983), Piero Sraffa (1898-1983), Pierangelo Garegnani (1930-2011) e Luigi Pasinetti) e da Cambridge americana (Paul Samuelson (1915-2009), Robert Solow, Frank Hahn (1925-2013) e Christopher Bliss). A controvérsia entre Friedrich A. Hayek (1899-1992) e Frank H. Knight (1885-1972), por outro lado, foi relativamente pouco estudada, apesar de sua importância histórica. A finalidade do presente ensaio é justamente realizar uma reconstituição histórica do debate entre Hayek e Knight acerca da teoria do capital, buscando compreender o debate em seus próprios termos.

Na seção 2, faz-se um breve resumo da controvérsia em ordem cronológica, artigo por artigo. A partir do contraste das teorias de ambos os autores, é feita uma análise comparativa das concepções gerais de capital dos autores na seção 3.1. Relata-se, na seção 3.2, a discussão gerada em torno da legitimidade da classificação dos fatores de produção em fatores originais e fatores produzidos. Na seção 3.3, fala-se sobre a divergência dos autores em relação ao papel do tempo no processo produtivo, com ênfase nas discussões sobre a definição e relevância do conceito de período de produção (3.3.1) e da existência ou não de uma correspondência entre investimentos e dimensão temporal da produção (3.3.2). Na seção 3.4, são explicadas as posições de Hayek e Knight sobre o método e escopo da ciência econômica e suas implicações na controvérsia. Por fim, na seção 4, apresentam-se as considerações finais e conclusões do trabalho.

\section{II - Resumo Cronológico do Debate}

A teoria do capital de Hayek pertence à tradição da teoria austríaca do capital, comumente associada a autores como William Stanley Jevons (1835-1882), Eugen von Böhm-Bawerk (1851-1914) e Knut Wicksell (1851-1926). A teoria do capital de Knight, por sua vez, possui clara influência da concepção de capital de John Bates Clark (1847-1938). Ao longo da década de 1930, essas duas tradições de pensamento se confrontaram através de uma acalorada discussão entre Hayek e Knight, a qual retomou muitos pontos já debatidos na controvérsia anterior entre Böhm-Bawerk e J. B. Clark ocorrida cerca de três décadas antes, entre 1893 e 1907.

A controvérsia entre Hayek e Knight deu-se através de cinco artigos publicados entre 1933 e 1936: Capitalist Production, Time, and the Rate of Return (1933), On The Relationship Between Investment and Output (1934), Capital, Time, and the Interest Rate (1934), Professor Hayek and the Theory of Investment (1935) e The Mythology of Capital (1936). O debate inicia-se em 1933 com a publicação de Capitalist Production, Time, and the Rate of Return. Nesse artigo, Knight ataca a teoria do capital associada a Jevons, Böhm-Bawerk, Wicksell e Hayek, dizendo que tal teoria envolvia confusões fatais e que ela só poderia ser defendida sob condições tão divergentes dos fatos básicos da vida econômica moderna que seria muito imprudente utilizá-la como ferramenta de análise ${ }^{1}$.

\footnotetext{
${ }^{1}$ KNIGHT, F. Capitalistic Production, Time, and the Rate of Return. In: Essays in Honour of Gustav Cassel.
} 
Ao longo do artigo, Knight realiza uma série de definições de termos que visam esclarecer sua própria posição sobre o capital e, ao mesmo tempo, explicitar os equívocos da teoria austríaca. Segundo ele, o fim de toda atividade econômica é a satisfação de desejos, uma mudança de estado no sujeito econômico, mudança esta que é produzida e mantida por algum período de tempo e por alguma agência econômica direta, a qual pode ser um objeto ou uma pessoa. O uso de uma agência direta é chamado de consumo do ponto de vista do processo e de serviço do ponto de vista daquilo que é consumido. Consumo e serviço têm uma dimensão temporal: eles são taxas ${ }^{2}$.

Através das escolhas de dispêndio dos consumidores, os diferentes tipos de serviços seriam reduzidos a um denominador comum compatível com os preços de cada momento. Compras e vendas, porém, ocorrem geralmente de forma discreta em pontos no tempo, e não de forma contínua. Logo, o que entraria na troca não seria um fluxo como tal, mas uma quantidade absoluta, mais especificamente o valor do direito a um fluxo de serviço de alguma magnitude por algum período de tempo. Com as escolhas de dispêndio dos consumidores:

[...] the comparisons made privately by individuals become objectified, so that it is possible to speak of measurement only through purchase and sale in a market. Purchase and sale are almost never continuous, but rather take place as "events" at a point in time. What enters into exchange and gets measured is, therefore, not a flow as such but an absolute quantity, in fact the "value" of a right to some stream of service of some magnitude over some time period ${ }^{3}$.

Daí surge o conceito de riqueza, cujo atributo mais importante seria o valor:

The primary economic reality is consumption income; but since wealth is what is ge-

London: George Allen and Unwin, 1933. p. 327-342. Cit. p. 211.

\footnotetext{
2 Idem. Ibidem., p. 213-14.

${ }^{3}$ Idem. Ibidem., p. 214-15.
}

nerally measured, we must have a name for the stream of service defined in terms of wealth, by reinversion, as it were. The resulting conception is consumption-income, a stream of exchange value, which must therefore be defined dimensionally as wealth divided by time, or, accurately, the derivative of wealth magnitude with respect to time ${ }^{4}$.

O capital pode ser definido como sendo idêntico à riqueza, enxergada sob o ponto de vista do fluxo de consumo da qual ela é um valor capitalizado, e não simplesmente como uma quantidade de valor de troca. Knight enuncia, então, três "fatos básicos" que deveriam compor uma sólida teoria do capital. $\mathrm{O}$ primeiro fato seria o princípio da "capitalização": deve haver uma taxa uniforme de renda no tempo, para cada item da riqueza, supondo condições competitivas:

Any item which represents an income lower than that of any other item of equal value will be exchanged for the latter, and differences eliminated ${ }^{5}$.

O segundo fato básico seria a oportunidade aberta de investimento e, adicionalmente, que muito investimento líquido teria sido feito, em qualquer momento, em todas as economias competitivas das quais se teria conhecimento histórico. Sob essas condições: "[...] the same agencies [...] which yield consumption services can be used, and in large measure constantly are used, instead to create capacity to yield such services, in greater quantity [...] but of course at a later date" ${ }^{\prime \prime}$.

O terceiro fato é que, sob as condições citadas anteriormente:

[...] any time segment of (money) income due at any future interval is economically equivalent to a uniform, perpetual income, beginning the moment the decision is made to convert the one into the other. The owner of such a prospective income can extend it

\footnotetext{
${ }^{4}$ Idem. Ibidem., p. 215.

${ }^{5}$ Idem. Ibidem., p. 217.

${ }^{6}$ Idem. Ibidem., p. 218.
} 
back to the present by borrowing from the stream of new saving of the system as a whole, and can extend it beyond its original terminus into the future without limit by investment, with corresponding reduction in its volume over the original interval ${ }^{7}$.

Adicionalmente, numa sociedade em que incrementos líquidos de riqueza através de investimento estão sendo feitos, todo rendimento de riqueza seria, em essência, perpétuo. Se um indivíduo qualquer, que fez algum investimento, decide "consumi-lo", nenhuma conversão real de riqueza em renda seria feita, mas apenas uma redução da conversão líquida de renda em riqueza, realizada pelos investimentos feitos pelos outros indivíduos ${ }^{8}$. Disso se vê que Knight trata o capital como um fundo perpétuo de valor.

Feitas essas definições (e algumas outras de pouca importância para nossos propósitos), Knight volta-se para a crítica da teoria austríaca. As críticas de Knight nesse artigo podem ser resumidas em três: i) A relação existente entre trabalho e capital no processo produtivo é uma relação de cooperação simultânea. Em nenhum sentido se pode distinguir entre fatores primários e secundários, pois nenhum deles é anterior ao outro; ii) Não há ciclo de produção ou período de produção que possua duração ou significado determinados. Numa perspectiva "estacionária", o equipamento produtivo da sociedade gera serviços, os quais, por sua vez, são consumidos ao mesmo tempo em que são produzidos. Numa perspectiva histórica, a criação do sistema produtivo e de seus componentes, o capital (que inclui a terra) e o trabalho, foi um processo cumulativo e ininterrupto no qual todos os instrumentos produtivos existentes a cada instante participam de forma cooperativa"; iii) A teoria do capital não tem relação apa-

\footnotetext{
${ }^{7}$ Idem. Ibidem., p. 218-19.

${ }^{8}$ Idem. Ibidem., p. 217-19.

${ }^{9}$ Idem. Ibidem., p. 212.
}

rente com a teoria dos ciclos, pois ela não lança luz sobre a questão da causalidade dos movimentos de expansão e contração dos fluxos de poupança para investimento, os quais constituiriam um aspecto principal dos booms e depressões ${ }^{10}$.

Em 1934, o artigo On The Relationship Between Investment and Output de Hayek é publicado. Nele, Hayek não lida diretamente com as críticas à teoria "austríaca" do capital, mas diz que muito do que escreveu consiste em réplicas implícitas a diversas críticas, entre elas, as feitas por Knight em Capitalist Production $^{11}$.

Para Hayek, o valor do estoque de capital concebido como o valor descontado dos produtos futuros esperados, ou concebido como o resultado do investimento de fatores de produção por determinados períodos de tempo são duas maneiras diferentes de representar a mesma coisa. Ambas as abordagens alternativas, para se mostrarem realmente úteis, necessitariam de uma análise detalhada do que Hayek chama de estrutura temporal de produção, ou seja, dos diferentes períodos os quais cada serviço individual deve ser descontado ou dos diferentes períodos durante os quais cada unidade de fator é investida ${ }^{12}$.

Através da análise da estrutura temporal de produção, Hayek tenta estabelecer uma relação entre as assim chamadas teorias "marshalliana" e "austríaca" do capital. Há duas formas diferentes através das quais o tempo pode ser relevante para a produção de um serviço final para o consumidor, ou seja, para que seja um bem de consumo: a duração do processo de produção e o tempo no qual o bem de capital gerará seus serviços. A distinção entre essas duas formas em que o fator tempo entra na produção de bens de consumo encontra correspondência na distinção

\footnotetext{
${ }^{10}$ Idem. Ibidem., p. 226.

11 HAYEK, F. A. On the Relationship between Investment and Output. Economic Journal, Vol. 44 (1934): 207-31. Cit. p. 208.

${ }^{12}$ Idem. Ibidem., p. 207.
} 
entre bens em processo e bens duráveis, respectivamente. Para cada um desses casos, há uma diferente magnitude que pode ser considerada como uma variável independente dada:

[...] in each of these two cases only one of the two fundamental magnitudes to be discussed here can be considered as a directly given independent variable, while each can be derived from the other only if the rate of interest is given, and is therefore in a sense a mere construction $^{13}$.

Se o capital for pensado como sendo composto unicamente por bens duráveis, a magnitude dada será a função de produto. Por outro lado, se o capital for pensado como sendo composto unicamente em termos de bens em processo, a magnitude dada será a função de investimento (que se trata de uma formulação mais exata do que se costumou chamar de período de produção). ${ }^{14}$

Under these circumstances it is not surprising that of the two schools mentioned above, that which thought of capital almost exclusively as of durable goods [the "Marshallian" School] concentrated almost exclusively on the one of these magnitudes, the output function (although this concept has not been clearly formulated by it), while the other school [the "Austrian" School], which thought of capital primarily in terms of goods in process, made the other magnitude, the investment [...], the starting-point of their attack $^{15}$.

A função de investimento (investment function) e a função de produto (output function) não devem ser confundidas com a familiar função de produção (production function):

\footnotetext{
${ }^{13}$ Idem. Ibidem., p. 209.

${ }^{14}$ Hayek define a função de investimento e a função de produto da seguinte forma: "[T]he investment function [...] describes how long we have to wait for the product of the different units of "labour" [but] doesn't show us how long we have to wait for the different units of the output [...]. [T] he output function [...] describes the latter phenomenon" (HAYEK, op. cit., 1934, p. 212).

${ }^{15}$ Idem. Ibidem., p. 209.
}

[...] the investment function under discussion here as well as the output function to be discussed later are entirely different from the familiar production functions which describe the dependence of the quantity of output on changes in the method of production. The types of functions used here serve merely to describe one single process of this sort and cannot by themselves be used to show the effects of changes in the method of production. ${ }^{16,17}$

No caso de bens em processo e supondo a aplicação de um fator "original" homogêneo, as condições de equilíbrios não serão que os produtos marginais de cada unidade de fator original se igualem, mas sim que os produtos marginais sejam iguais em valor, ou seja, que haja igualdade entre os produtos marginais descontados pelo período em que cada unidade foi investida. Dessa forma, uma mudança na taxa de juros implica em uma mudança no valor relativo atribuído a cada unidade de fator original o que acarreta uma transferência de fatores entre estágios de produção. Uma diminuição na taxa de juros, por exemplo, terá como consequência um aumento do valor dos fatores originais dos estágios mais iniciais relativamente ao dos fatores dos estágios finais, o que por sua vez provoca uma transferência de fatores originais para os estágios mais iniciais ${ }^{18}$. No caso de bens duráveis, Hayek considera que a situação é, de certa forma, similar. Uma diminuição da taxa de juros, nesse caso, implica que uma maior parte dos serviços mais distantes desses bens serão atribuídos ao fator original, pois menos será descontado em juros:

A lowering of the rate of interest, e.g., which will make the investment curve less curved, means that a greater part of the more dis-

\footnotetext{
${ }^{16}$ Idem. Ibidem., p. 211.

17 Hayek faz, então, uma longa discussão técnica dos casos de bens duráveis e de bens em processo, a qual não temos interesse direto aqui, pois essa foi explicitamente ignorada nas respostas subsequentes de Knight.

${ }^{18}$ Idem. Ibidem., p. 222.
} 
tant services of the goods will be attributed to "labour" (because less will be deduced for interest) or that a smaller part of the future stream of services will be sufficient to attract a unit of "labour" to the production of such goods. More goods (or, where possible, more durable goods) of the kind will be produced simply because the more distant part of the expected services will play a greate role in the considerations of the entrepreneur and will lead him to invest more on account of these more distant returns ${ }^{19}$.

Dessa discussão sobre o efeito da taxa de juros sobre a estrutura temporal de produção, fica claro que, para Hayek, cada taxa de juros irá direcionar os investimentos em certa direção: uma taxa de juros menor envolverá uma quantidade de capital maior (uma estrutura de investimento mais "longa") e uma taxa de juros maior envolverá uma quantidade de capital menor. Vê-se, assim, que a função da taxa de juros seria a de limitar a produção aos métodos mais lucrativos para os quais a quantidade disponível de capital é suficiente. E é aqui onde Hayek revela seu interesse primário no estudo da teoria do capital: a análise dos aspectos dinâmicos da estrutura temporal de investimento, a qual está na base da teoria hayekiana dos ciclos econômicos. Para Hayek, dada uma economia inicialmente estacionária, um alongamento (encurtamento) na estrutura de investimento que não tenha contraparte em uma diminuição (aumento) no dispêndio de bens de consumo, mas sim uma contraparte no desvio para baixo (para cima) da taxa de juros em relação a sua posição de equilíbrio, gera um desequilíbrio entre preços e custos o qual tende a restaurar as condições de equilíbrio não mantidas pelos juros ${ }^{20}$.

De acordo com Hayek, a maneira de exposição de Böhm-Bawerk gerou muita confusão sobre o conceito de período de produção, de forma que esse foi, erroneamente, interpretado num sentido ex post ou histórico. Mas o

\footnotetext{
${ }^{19}$ Idem. Ibidem., p. 224-25.

${ }^{20}$ Idem. Ibidem., p. 225-26.
}

conceito relevante não é a duração do processo que resultou no produto corrente, mas a extensão dos períodos para os quais estão sendo investidos os fatores de produção ofertados correntemente. Em outras palavras, a análise é ex ante e não ex post. Quando mudanças não antecipadas ocorrem depois de o capital já ter sido investido em uma forma específica, todo o investimento futuro será influenciado pela existência desses bens de capital, de forma que o movimento em direção ao equilíbrio será, na melhor das hipóteses, um movimento assintótico. E é exatamente por isso que a interpretação ex post do período de produção sempre gera conclusões absurdas. Só por um acidente bastante improvável o valor do capital real existente corresponderá ao seu custo histórico de produção. A proposição essencial da teoria não é essa, mas sim que o valor dos bens de capital existentes tem relação definida com a forma com que os fatores presentes estão sendo investidos ${ }^{21}$. É essa perspectiva ex ante que se deve ter em mente na análise do capital.

Por fim, Hayek faz uma crítica implícita a Knight ao defender que é uma necessidade urgente no campo da teoria do capital que os economistas se libertem da ideia de capital como sendo uma massa homogênea, uma dada quantidade de valor que preserva sua magnitude independentemente do valor dos bens reais no qual ela consiste. E aqui tocamos num ponto bastante caro à teoria austríaca: heterogeneidade do capital. É razoável supor que todos os bens de capital existentes em um dado momento são resultado de um processo histórico que constantemente coloca esses bens de capital para usos diferentes dos que eles foram originalmente projetados, de modo que a forma real que o capital tomará será bem diferente da que ele teria se fosse possível construir a estrutura do zero, com a ajuda de um fundo equivalente de capital livre ${ }^{22}$.

Ainda em 1934, Knight publica o artigo Capital, Time, and the Interest Rate. Nesse arti-

\footnotetext{
${ }^{21}$ Idem. Ibidem., p. 228.

${ }^{22}$ Idem. Ibidem., p. 227.
} 
go, o autor renuncia ao que considera serem as proposições fundamentais de uma teoria sólida do capital. Reitera as críticas à teoria austríaca, buscando contrastar essa teoria com sua própria teoria. As doutrinas a serem rejeitadas por uma teoria sólida, diz-nos Knight, incluem todas as noções de alguma relação definida entre a quantidade de capital e a "duração do processo produtivo" ou o "tempo", que não seja a forma básica de uma dimensão na soma de algum processo. A única forma em que se deveria levar em conta o "tempo" seria, portanto, o reconhecimento de que variáveis de fluxo (p. ex. o consumo) consistem em taxas aplicadas por determinados períodos de tempo. Enfatiza, também, que se deve rejeitar a ideia de que o processo produtivo possua qualquer duração de tempo determinada dentro das condições comuns da indústria capitalista $^{23}$.

Há três fatos empíricos que formariam a base de uma teoria sólida do capital: 1) o fato "tecnológico" de que é possível aumentar o volume da produção através do investimento; 2 ) o processo de investimento é realizado em bases competitivas nas sociedades às quais a teoria dos preços padrão se refere; e 3) o fato "institucional" de que existe um mercado geral onde recursos produtivos e rendas pecuniárias são comprados e vendidos livremente. Sob essas condições, emerge o fenômeno de contabilidade de capital, o qual consiste na conversão de todos os recursos produtivos comercializáveis em uma quantidade pura de "capital" ${ }^{24}$. Do ponto de vista econômico, nenhuma classificação de fatores de produção possuiria qualquer validade. A única distinção importante a ser feita entre os fatores é a de tipo puramente "institucional": a distinção entre fatores comercializáveis (que constituem a maioria absoluta) e fatores não comercializáveis (p. ex. os seres humanos/tra-

${ }^{23}$ KNIGHT, F. Capital, Time, and the Interest Rate. Economica, n.s., Vol. 1 (1934): 257-86. Cit. p. 257-59.

${ }^{24}$ Idem. Ibidem., p. 258. balhadores). A implicação dessa distinção é que os fatores comercializáveis estão sujeitos à contabilidade de capital, enquanto os fatores não comercializáveis não estão ${ }^{25}$.

Reconhecendo esses fatos empíricos, uma teoria sólida do capital e dos juros poderia ser resumida em quatro proposições: 1) A quantidade de capital "em" qualquer item é o "valor presente", no momento da valoração, de seus rendimentos futuros, a uma dada taxa de juros uniforme. 2) A quantidade de capital "em" qualquer item é também determinada, sob condições de planejamento e previsibilidade perfeitos, por seu "custo de construção". Nesse custo está incluso, além dos pagamentos das agências utilizadas, o "custo de posse" $^{\prime \prime}$ acumulado $^{26}$. 3) Todo incremento incorrido de custo deve gerar um retorno de mesma taxa por todo o período em que tal incremento é investido. Logo, o custo de posse é acumulado à mesma taxa que se usa para chegar ao valor presente de qualquer incremento de renda futura. 4) Das três proposições anteriores, segue que o custo de construção é igual ao valor presente do rendimento antecipado, quando a taxa com a qual os custos de posse são acumulados é a mesma taxa pela qual o rendimento futuro é descontado. 5) Onde quer que exista liberdade de escolha entre oportunidades de investimento e um livre mercado de compra e venda de itens de capital, todo o "investimento" (criação de um item gerador de renda) será feito sob a condição de que sua taxa de retorno será a máxima possível dentro das condições técnicas vigentes ${ }^{27}$.

Numa sociedade progressista, tornar-se-ia mais fiel às relações essenciais tomar o ponto de vista da conta de capital "como

${ }^{25}$ Idem. Ibidem., p. 264-25.

26 "The second element is an accumulated 'carrying charge' on each increment of such outlays from the moment when each is incurred to the moment of valuation of the instrument" (Idem. Ibidem., p. 260). Knight não expõe uma definição de custo de posse (carrying charge) e não fica claro o que exatamente ele quer dizer com o termo.

${ }^{27}$ Idem. Ibidem., p. 260-1. 
tal", ou seja, levar em conta a quantidade de capital pertencente a uma empresa ou a um indivíduo sem fazer nenhuma referência aos instrumentos concretos nos quais o capital está "incorporado". Desse ponto de vista, o capital é inerentemente perpétuo. Se um instrumento particular de capital exaure-se (ou, por qualquer outra razão, deixa de ser rentável), sua substituição por outro(s) instrumento(s) de mesma capacidade de rendimento tem que ser tomada como um detalhe tecnológico dado. Adicionalmente, também sob o ponto de vista contábil, não há diferença entre manutenção e substituição: eventuais substituições são inclusas sob a categoria de manutenção ${ }^{28}$.

Uma decisão individual de desinvestimento e consumo do capital terá como efeitos apenas uma leve redistribuição de propriedade, e a eliminação de uma pequena parcela de crescimento que teria ocorrido, caso ele não tivesse tomado essa decisão. Uma vez produzido, um item de capital se torna uma fração indistinguível da quantidade total de capital do sistema econômico ${ }^{29}$. A "duração do período de produção" não tem nenhum significado de fato. De forma idêntica a feita anteriormente por J. B. Clark, Knight argumenta que, enquanto o capital for mantido através da substituição dos bens de capital (caso esses tenham vida limitada) por outros com mesma capacidade de rendimento, a durabilidade ou vida útil de um bem é apenas um detalhe técnico. Tornar mais durável e aumentar o período de construção de um item de riqueza são apenas duas entre infinitas formas de fazer com que esse item tenha um retorno líquido maior. Para Knight, o que a "escola de Böhm-Bawerk" faz é selecionar esses dois detalhes, os quais possuem tanta importância quanto infinitos outros detalhes, dar a ambos em conjunto a falsa designação de duração do processo produtivo e fingir que esse é o único fator envolvido no cálculo racional do investimento ${ }^{30}$.

\footnotetext{
${ }^{28}$ Idem. Ibidem., p. 264.

${ }^{29}$ Idem. Ibidem., p. 265.

${ }^{30}$ Idem. Ibidem., p. 270.
}

Knight argumenta que é impossível determinar quando foi iniciada a produção de um dado incremento de consumo. Analogamente, também seria impossível determinar quando os resultados de um dado incremento na atividade produtiva serão consumidos. Se a produção é considerada como um processo ao longo do tempo, seu início e fim deveriam, logicamente, equivaler ao início e fim da vida econômica. Por outro lado, no único sentido de temporalidade em que a análise econômica torna-se possível, a produção e o consumo seriam simultâneos. Para tanto, a produção deveria ser definida como a prestação (rendimento) de serviços e é autoevidente que um serviço só pode ser consumido ao mesmo tempo em que é prestado. Um serviço que cria valor além da satisfação instantânea o faz criando alguma forma de capital, que, por sua vez, irá posteriormente produzir satisfação. Dessa forma, desconsiderando os investimentos e desinvestimentos líquidos, produção e consumo são instantaneamente simultâneos ${ }^{31}$. Em 1935, Knight publica o artigo Professor Hayek and the Theory of Investment, o qual é bastante similar a Capital, Time, and the Interest Rate, cobrindo praticamente os mesmos tópicos, fato que é admitido por Knight e que justifica citando Hebert Spencer (1820-1903): "Only by varied iteration can alien concepts be forced on reluctant minds" 32 . Há uma diferença, porém, entre esse artigo e o anterior que é de interesse do presente trabalho: em Professor Hayek, Knight faz referências e críticas diretas a Hayek.

Logo de início, Knight declara que não conseguiu localizar nenhuma parte de The Relationship Between Investment and Output em que Hayek dê aos leitores alguma razão para que se acredite em sua teoria. Segundo Knight, quando Hayek diz que uma diminui-

\footnotetext{
${ }^{31}$ Idem. Ibidem., p. 276.

32 Spencer, H. The Data of Ethics. 1879. The Online Library of Liberty. Disponível em: <http://oll. libertyfund.org/title/331>. Citado em: KNIGHT, Frank. 1935. Professor Hayek and the Theory of Investment. Economic Journal, Vol. 45 (1935): 77-94.
} 
ção dos juros pode levar à produção de mais bens duráveis (ou, quando possível, de bens mais duráveis), ele estaria se "rendendo". Se a questão do período de produção fosse levada a sério, perceber-se-ia que em nenhum dos sentidos discutidos por Hayek em seu artigo o investimento necessariamente envolve ou é equivalente a um aprofundamento da estrutura temporal de investimento, e muito menos a um prolongamento do processo produtivo. Knight argumenta que novos investimentos não envolvem necessariamente nem um aumento da durabilidade média dos bens nem em um aumento do período médio de construção desses bens. A produção de mais bens duráveis, para Knight, não significaria nenhuma mudança permanente nem na função de produto, nem na função de investimento, da forma como foram definidas por Hayek ${ }^{33}$. Em outras palavras, produzir mais bens duráveis do mesmo tipo não implicaria em um alongamento da estrutura temporal do capital.

Para avaliar a afirmação de Hayek de que ele teria resolvido as objeções à sua teoria, a questão importante não é o efeito de um aumento do investimento sobre a estrutura temporal do investimento, mas seu efeito sobre o período de produção, pois é essa a relação postulada por Böhm-Bawerk e seus seguidores $^{34}$. A análise correta nos mostra, porém, que a quantidade de capital não possui nenhuma relação definida com sua durabilidade ou com qualquer outro intervalo de tempo definível. A soma do período de produção e vida útil média de instrumentos individuais de capital não é uma quantidade determinada em si mesma nem é significante para a teoria. Sob condições modernas simplesmente não existe nenhum ciclo de produção. Capital é um conceito orgânico e integrado. A própria noção de que o investimento em um instrumento particular gera retornos periódicos em forma de produto, dando ao dono liberdade para es-

\footnotetext{
${ }^{33}$ Knight, Frank. 1935. Professor Hayek and the Theory of Investment. Economic Journal, Vol. 45 (1935): 77-94. Cit. p. 77-78.

${ }^{34}$ Idem. Ibidem., p. 79.
}

colher se quer ou não reinvesti-lo, não passa de uma ilusão. Uma parte de uma máquina não pode ser liquidada sem que se liquide a máquina inteira. E a situação é análoga em relação à máquina, vista como uma "parte" de uma organização produtiva integrada ${ }^{35}$.

Em sociedades estacionárias ou progressistas, pequenos incrementos de capital são, de fato, liquidados do ponto de vista do proprietário individual, mas nenhuma liquidação real ocorre do ponto de vista agregado. Isso ocorreria porque um proprietário individual desejoso por consumir capital apenas vende-o para outro proprietário, de modo que a organização produtiva não é afetada. Numa depressão, por outro lado, a liquidação que ocorre é quase inteiramente uma conversão em dinheiro, e não em consumo corrente (ocorre, primordialmente, liquidação pecuniária, e não liquidação real) ${ }^{36}$. E é nessa conexão que o tempo torna-se importante, pois surge a questão da mobilidade do capital, liberdade para transferi-lo para outro uso. Mas como o que as pessoas querem, numa depressão, é converter seus investimentos em dinheiro, isso se torna um problema a ser estudado pela teoria da moeda, e não pela teoria do capital ${ }^{37}$. Uma depressão, em sua fase crítica na qual há desemprego de fatores produtivos humanos e não humanos, envolve o comprometimento errôneo de recursos, comprometimento sustentado pela imobilidade. Mas essa questão é essencialmente uma de desajuste de preços, sustentado por rigidez de preços. Se o trabalho fosse móvel e os salários flexíveis, nenhuma rigidez da estrutura do capital criaria desemprego de capital ou de trabalho, embora a eficiência pudesse ser bastante reduzida ${ }^{38}$.

Como já foi dito, em toda a sociedade que, como um todo, mantém seu capital total quantitativamente intacto, toda liquidação é uma transferência de investimento entre dife-

\footnotetext{
${ }^{35}$ Idem. Ibidem., p. 83.

${ }^{36}$ Idem. Ibidem., p. 83.

${ }^{37}$ Idem. Ibidem., p. 91.

${ }^{38}$ Idem. Ibidem., p. 94.
} 
rentes proprietários. Knight, porém, reconhece que não pode ser dada uma definição exata à noção de manter o capital quantitativamente intacto, mas se justifica dizendo que isso é verdade para todas as análises quantitativas em economia. Além disso, o que é importante para a maioria dos problemas não é o total num sentido absoluto. Apenas é necessário identificar se há adição ou subtração em uma conta que não encontra contrapartida exata em alguma outra conta ${ }^{39}$.

Nenhuma análise racional do processo econômico é possível sem fazer uma distinção entre a "produção" de uma nova "planta produtiva" e a produção no sentido de utilizar essa planta para obter produto final. $\mathrm{O}$ uso da planta na obtenção de produto consumido em qualquer intervalo de tempo tem que incluir a manutenção da planta (o que inclui substituição de itens particulares da planta). Dessa forma, investimento é um sinônimo de sobremanutenção e desinvestimento um sinônimo de submanutenção. No sentido de utilização de uma planta, a produção e o consumo são simultâneos, e o período de produção do produto consumido é zero. Por outro lado, no sentido de produção de uma determinada planta, o período de produção é toda a história passada. Do ponto de vista econômico, tudo em existência em qualquer momento que possua capacidade produtiva é, sem exceção, um fator primário ou dado. Do ponto de vista histórico, por outro lado, tudo foi produzido durante o processo econômico como um todo, se estendendo a partir do início da história econômica ${ }^{40}$.

Finalmente, em 1936, ocorre a publicação do artigo de Hayek, o qual marca o final da controvérsia: The Mythology of Capital. O título desse artigo trata-se de uma referência a um trecho de um artigo de Böhm-Bawerk, no qual este, referindo-se a J. B. Clark, diz:

With every respect for the intellectual qualities of my opponent, I must oppo-

\footnotetext{
${ }^{39}$ Idem. Ibidem., p. 90.

${ }^{40}$ Idem. Ibidem., p. 85.
}

se his doctrine with all possible emphasis, in order to defend a solid and natural theory of capital against a mythology of capital ${ }^{41}$.

Hayek identifica grande similaridade entre os ataques que Knight faz ao conceito de período de produção e aqueles feitos por Clark em seu debate com Böhm-Bawerk. Mas, diz-nos Hayek, seu interesse não é de defender as visões de Böhm-Bawerk, cuja teoria tentou incorporar o fator tempo de forma muito simplificada, o que não permitiu que ele se libertasse do conceito de capital como um determinado fundo. Boa parte da confusão nessa área de teoria do capital deve-se a esse tratamento inadequado da questão. Hayek chega até a dizer que tem total simpatia por aqueles que veem o conceito de período médio de produção como uma abstração sem sentido que possui pouca ou nenhuma relação com o mundo real. Knight erra ao não direcionar seu ataque ao que há de errado na articulação tradicional dessa teoria, tentando substituir esse tratamento do tempo por um mais adequado. Ao invés de ao menos tentar fazer uma análise do fenômeno real, Knight introduz um pseudoconceito destituído de conteúdo e sentido, o qual ameaça ocultar todo o problema numa névoa de palavras ${ }^{42}$.

O erro básico de Knight é, para Hayek, a ideia do capital como um fundo que se mantém automaticamente e que, a partir do momento que certa quantia de capital é criada, a necessidade de sua reprodução não representa nenhum problema econômico. Não poderíamos nem nos perguntar sobre as razões pelas quais o capital se automantém, pois sobre condições estacionárias ou progressistas, isso é axiomático. Knight não usa a palavra

${ }^{41}$ BÖHM-BAWERK, E. v. Capital and Interest Once More: II. A Relapse to the Productivity Theory. The Quaterly Journal of Economics, Vol. 21, No. 2 (Feb., 1907): 247-82. Citado em Hayek, F. A. The Mythology of Capital. Quarterly Journal of Economics, Vol. 50 (1936): 199-228. Cit. p. 282.

${ }^{42}$ HAYEK. The Mythology of Capital. p. 199-200. 
"automática" para caracterizar a manutenção do capital, mas sua insistência que a substituição do capital deve ser tomada como um "detalhe técnico" só pode ser interpretada como querendo dizer que, do ponto de vista do economista, ela é automática. Contra isso e também contra a crítica de Knight de que o fator tempo seria mais um entre infinitos detalhes igualmente importantes, Hayek afirma que: 1) Todos os problemas discutidos sobre a designação de "capital" surgem do fato de que parte do equipamento produtivo é não permanente e deve ser deliberadamente substituída; 2) Não existe sentido algum em falar do capital como algo permanente que existiria independentemente dos bens de capital nos quais consiste; 3) Um incremento de capital sempre significa uma extensão da dimensão temporal do investimento; 4) Os três itens anteriores são relevantes para a compreensão não só da transição para métodos mais capitalistas, mas também de como a limitação da oferta de capital limita as possibilidades de aumento do produto sob condições estacionárias ${ }^{43}$. Em outras palavras, as considerações dos itens 1 a 3 seriam relevantes tanto para a comparação de dois estados estacionários distintos, quanto para a análise da transição de um estado para o outro.

Antes de tentar refutar as críticas recebidas, Hayek discute as visões que ele não defende, mas que são erroneamente associadas a ele por Knight e outros autores. Esclarece que: 1) Sua análise do capital pressupõe conhecimento técnico constante. Apenas quando lidamos com incrementos do produto que dependem da disponibilidade de certa quantia de capital, incrementos estes que eram anteriormente impossíveis somente por causa da insuficiência da oferta de capital, é que surge a ideia de que um aumento da roundaboutness ${ }^{44}$ implica num aumento da produtividade; 2) Os períodos que são aumentados com a elevação dos investi-

\footnotetext{
${ }^{43}$ Idem. Ibidem., p. 203-04.

44 O termo roundaboutness designa um método de produção indireto. (N. E.)
}

mentos são os períodos durante os quais fatores particulares são investidos (período de investimento), e não o período de produção de um bem final particular (período de produção). Por exemplo, é possível aumentar o período de investimento, sem que nenhum período de produção se altere, através da transferência de fatores de indústrias onde eles são investidos por períodos mais curtos para indústrias onde eles são investidos em períodos mais longos; 3) A descrição dos vários períodos para os quais fatores diferentes são investidos não pode ser reduzida a uma dimensão de tempo simples como o período médio de produção. Knight está enganado por achar que, ao mostrar as inconsistências do período médio de produção, ele justifica a retirada da ideia de tempo da teoria do capital; 4) A teoria defendida é ex ante e não ex post. Os períodos relevantes são os períodos futuros, e nunca os períodos passados durante os quais certos fatores "originais" foram investidos; 5) A própria distinção entre fatores originários/primários e fatores produzidos é irrelevante para o conceito de função de investimento. Pode-se, por exemplo, descrever os vários períodos de para os quais todos os fatores existentes no início de um período (originais e produzidos) são investidos ${ }^{45}$.

O próprio conceito de capital surgiria do fato de que, quando recursos não permanentes são usados na produção, a provisão para a substituição desses recursos deve ser feita se é desejado o consumo continuado de uma mesma renda. Ou seja, se é desejado um fluxo constante de bens de consumo, parte do produto deveria ser devotada à reprodução dos recursos não permanentes utilizado na produção daqueles. Entretanto, mesmo se considerarmos como o caso "normal" que as pessoas irão reproduzir esses recursos não permanentes, com o objetivo de manter uma renda perpétua, isso não significa que o capital pode ser considerado perpétuo em algum sentido. Não há sentido algum em dizer que

\footnotetext{
${ }^{45}$ Idem. Ibidem., p. 205-09.
} 
o agregado de todos os recursos não permanentes torna-se uma entidade permanente independentemente da escolha humana, a qual ainda falta explicar ${ }^{46}$.

O problema da teoria do capital seria explicar como a existência de um dado estoque de recursos não permanentes torna possível sua substituição por instrumentos novos e, ao mesmo tempo, limita a extensão em que isso pode ser feito. E isso geraria outra questão: em que sentido os diferentes bens de capital tem uma qualidade comum, que nos permite considerá-los como partes de um mesmo fator (ou seja, como um "fundo")? Se a afirmação de Knight de que o capital é permanente possui algum sentido, ela teria que significar que o capital é mantido quantitativamente intacto. Mas qual é o critério que determina se os bens novos são ou não equivalentes aos antigos que substituem, e o que nos garante que eles sempre o serão? Para essas perguntas, Knight não possui nenhuma resposta. Ele apenas evade o problema dizendo que à noção de manter o capital quantitativamente intacto não pode ser dada uma definição exata, mas que isso se aplica a todas as análises quantitativas em economia. A verdade é que a noção de manter o capital quantitativamente constante não é nem clara, nem indispensável. Pressupõe um comportamento dos empresários e capitalistas que, sob condições dinâmicas, será raramente razoável e, possivelmente, até mesmo impossível. Assumir que o capital é mantido quantitativamente constante é assumir algo que nunca ocorre, e nenhuma dedução feita a partir desse pressuposto terá qualquer aplicação no mundo real ${ }^{47}$.

Hayek também aponta que todas as deduções que Knight faz em seus artigos baseiam-se no pressuposto de previsão perfeita. Sob esse pressuposto, porém, os problemas da teoria do capital sequer surgiriam. Se assumirmos que a previsão perfeita existe desde o início dos tempos, apenas um plano original seria necessário no instante inicial, depois do qual não surgiria

\footnotetext{
${ }^{46}$ Idem. Ibidem., p. 214-15.

${ }^{47}$ Idem. Ibidem., p. 215-16.
}

nenhum problema de manutenção, substituição ou distribuição de capital. Mas também nunca surgiria nenhum outro problema econômico. Problemas econômicos, de qualquer tipo, só surgem quando há uma questão de como ajustar os meios disponíveis a uma situação nova e o mesmo vale no caso específico da questão de como usar de forma mais lucrativa um dado estoque de bens de capital. O conceito de capital como um fundo de determinada magnitude que se auto perpetua não possuiria, para Hayek, nenhuma aplicação fora do fictício estado estacionário. Mesmo assim, a ênfase que Knight põe na mobilidade de capital daria a impressão que ele quer aplicar tal conceito a fenômenos dinâmicos. Afinal, argumenta Hayek, nenhum problema de mobilidade de capital surge quando o futuro é sempre corretamente previsto ${ }^{48,49}$.

Após a publicação de The Mythology of Capital, o debate efetivamente termina. Knight recusa-se a escrever uma resposta a Mythology, dizendo que perdera o interesse na controvérsia. Posteriormente, também recusa o convite feito por Hayek para que Knight comentasse o manuscrito de Pure Theory of Capital, alegando ter outros compromissos ${ }^{50,51}$.

\section{III - Análise da Controvérsia}

\section{1 - Capital como fundo perpétuo vs. capital como estrutura}

Knight e Hayek defendiam concepções bastante distintas de capital. Knight tratava

\footnotetext{
${ }^{48}$ Idem. Ibidem., p. 225-28.

${ }^{49}$ Hayek, no entanto, considerava a previsão perfeita (cristalizada na figura teórica do ditador onisciente) um recurso metodológico indispensável ao estudo da teoria do capital. C.f. HAYEK, F. A. The Pure Theory of Capital. London: Routledge. 1941. p. 156.
}

${ }^{50}$ COHEN, A. J. The Hayek/Knight Capital Controversy: The Irrelevance of Roundaboutness, or Purging Processes in Time? History of Political Economy, Vol. 35, No. 3 (Fall 2003): p. 469-90, 2003.

${ }^{51}$ Há uma breve menção às posições de Knight em HAYEK. The Pure Theory of Capital. p. 93-94. 


\begin{tabular}{|l|c|c|}
\multicolumn{1}{l|}{} & Abordagem “marshalliana” & Abordagem “austríaca” \\
\hline $\begin{array}{l}\text { Forma com que o tempo é condição } \\
\text { para a produção de serviços }\end{array}$ & $\begin{array}{c}\text { Tempo durante o qual o produto } \\
\text { fornece seus serviços }\end{array}$ & $\begin{array}{c}\text { Tempo de duração do processo } \\
\text { de produção }\end{array}$ \\
\hline Tipo de bens enfatizado & Bens duráveis & Bens em processo \\
\hline $\begin{array}{l}\text { Variável independente } \\
\text { diretamente dada }\end{array}$ & Função de Produto & Função de Investimento \\
\hline $\begin{array}{l}\text { Variável derivada, dada uma taxa } \\
\text { de juros }\end{array}$ & Função de Investimento & Função de Produto \\
\hline
\end{tabular}

Tabela 1 - Abordagem "marshalliana" vs. abordagem "austríaca"

o capital como um fundo de valor homogêneo, permanente e que se autorreproduzia de maneira automática. Hayek, por outro lado, via o capital como uma estrutura de bens heterogêneos, enfatizando o caráter temporal dos processos produtivos. A chave para a compreensão da divergência entre ambos sobre o conceito de capital está na relação que estabelecem entre, de um lado, o capital e a quantidade de capital, e, do outro lado, os bens de capital concretos que compõem o capital.

Seguindo a tradição austríaca de Böhm-Bawerk e Wicksell, Hayek adota uma perspectiva longitudinal do capital, tratando a produção como um processo sequencial ao longo do tempo. Ele também toma emprestado e desenvolve abordagem da estrutura de capital de Wicksell. Uma das grandes diferenças entre Hayek e teóricos austríacos do capital que o antecederam é que ele tenta aumentar a generalidade da teoria, através da tentativa de incorporação de bens duráveis à análise. A teoria austríaca do capital, antes de Hayek, lidava somente com processos produtivos do tipo insumo ponto - produto ponto e insumo fluxo - produto ponto, ou seja, processos em que a produção pode ou não levar tempo, mas que o serviço do produto é consumido instantaneamente. A tentativa de incorporação dos bens duráveis ao esquema analítico austríaco feita por Hayek em 1934 corresponde à inclusão do trata- mento de processos do tipo insumo ponto - produto fluxo. Vejamos como, exatamente, Hayek faz isso.

Para Hayek ${ }^{52}$, há duas formas diferentes de conceber o valor do estoque de capital: como o valor descontado dos produtos futuros esperados ou como o resultado de investimento de fatores de produção por determinados períodos. Ambas essas formas, para que se mostrem úteis, tornam inevitável a análise da estrutura temporal de produção, estrutura esta que se compõe de dois aspectos: (1) os diferentes períodos para os quais os serviços individuais devem ser descontados e (2) os diferentes períodos durante os quais unidades individuais de fatores são investidas. A ênfase dada a um desses aspectos em detrimento do outro caracterizou as abordagens "marshalliana" e "austríaca" do capital, com a diferença de que cada uma dessas enfatizava um aspecto diferente.

O objetivo de Hayek era, justamente, estabelecer a relação entre essas duas abordagens, pois apenas a consideração cuidadosa dos dois aspectos da estrutura temporal de produção poderia lançar luz sobre a relação real. O denominador comum entre ambas as abordagens é que o ponto de partida da análise são os bens de capital e suas respectivas funções de produto ou funções de investimento. A partir desses bens de capital

\footnotetext{
${ }^{52}$ HAYEK, op. cit., 1934, p. 207.
} 
é que se determina o valor do estoque de capital, seja descontando o valor dos produtos futuros obtidos por bens duráveis, seja através da soma dos valores imputados dos bens em processo.

Knight define o capital como sendo idêntico à riqueza, enxergada sob o ponto de vista do fluxo de consumo da qual ela é um valor capitalizado, e não simplesmente como uma quantidade de valor de troca. Onde quer que esteja presente o fenômeno de contabilidade de capital, todos os recursos produtivos comercializáveis são convertidos em uma quantidade pura de capital ${ }^{53}$. Nesse processo, os diversos bens de capital heterogêneos são, portanto, reduzidos a um fundo homogêneo de valor ${ }^{54}$. Uma vez produzido, um item de capital torna-se uma fração indistinguível da quantidade total de capital do sistema econômico ${ }^{55}$.

Esse fundo, no entanto, não é só homogêneo, mas também é perpétuo. $\mathrm{O}$ argumento que Knight usa em prol dessa afirmativa é axiomático: numa sociedade em que estão sendo feitos incrementos líquidos de riqueza, todo rendimento de riqueza (e, portanto, também o valor presente do fluxo de todos esses rendimentos) é, "em essência", perpétuo ${ }^{56}$. Em outras palavras: onde há acumulação líquida de capital, podemos considerar o capital existente como sendo perpétuo e a formação líquida de capital como sendo um incremento desse capital perpétuo. Sob essas circunstâncias, quando um indivíduo "consome" parte de seu capital, evidentemente só está reduzindo o incremento líquido de capital agregado.

Ainda numa sociedade progressista, Knight argumenta que há maior fidelidade às relações essenciais se tomarmos o ponto de vista do capital enquanto tal, ou seja, se le-

\footnotetext{
${ }^{53}$ KNIGHT, op. cit., 1933, p. 218.

${ }^{54}$ Com a qualificação de que esse fundo deve ser olhado sob o ponto de vista do consumo do qual ele é um valor capitalizado.

${ }^{55}$ KNIGHT, 1934, p. 265

${ }^{56}$ Idem. Ibidem., p. 219.
}

varmos em conta a quantidade de capital sem fazer nenhuma referência aos bens de capital $\operatorname{concretos}^{57}$. Disto se segue que quaisquer características referentes aos bens de capital em si mesmos e às formas com que se relacionam devem ser tomadas como meros detalhes tecnológicos. Manutenção/substituição, durabilidade, período de construção, entre outros inúmeros fatores, são, portanto, vistos por Knight como detalhes de pouca relevância ${ }^{58}$. Logo, uma implicação disto é que, se um instrumento particular de capital se exaure, sua substituição por outro instrumento de mesmo valor deve ser assumida como dada ${ }^{59}$, ou seja, o capital se autorreproduz de maneira automática.

No caso de sociedades retrógradas, é possível aplicar a terminologia de Knight? Tratando disso, primeiramente, ele pinta essa possibilidade como sendo implausível, afirmando que em todas as sociedades competitivas de que se tem conhecimento histórico, sempre houve investimentos líquidos sendo feitos ${ }^{60}$. Posteriormente, Knight argumenta que, numa depressão, a liquidação que ocorre é "quase inteiramente" uma conversão em dinheiro, e não em consumo corrente, isto é, predomina a liquidação pecuniária, e não a liquidação real ${ }^{61}$.

O contraste entre as concepções de capital de Hayek e Knight nos revela uma discordância fundamental entre ambos a respeito do ponto de partida adequado da teoria do capital. Hayek parte dos bens de capital concretos e das relações que possuem entre si (enfatizando a relação de sequencialidade temporal em seus modelos formais) e, então, constrói o capital como uma estrutura de bens heterogêneos. Para Hayek, não se poderia falar sobre o valor de um estoque de capital

\footnotetext{
${ }^{57}$ Idem. Ibidem., p. 264.

${ }^{58}$ Idem. Ibidem., p. 264-70.

${ }^{59}$ Idem. Ibidem., p. 264.

${ }^{60}$ KNIGHT, op. cit., 1933, p. 218.

${ }^{61}$ KNIGHT, op. cit., 1935, p. 83.
} 
sem fazer referência aos valores dos bens de capital concretos que o compõem. Knight, por outro lado, parte do próprio capital, enquanto fundo de valor, tratando as características e relações dos bens de capital como detalhes tecnológicos. O ponto de partida de Hayek são os bens de capital; o de Knight é a própria quantidade agregada de capital (valor do estoque de capital).

\section{2 - Fatores originais vs. produzidos}

Uma das críticas que Knight faz à teoria austríaca é que não se pode distinguir entre fatores primários e secundários ou, alternativamente, entre fatores originais e produzidos. A relação entre capital e trabalho é do tipo de cooperação simultânea, de modo que nenhum fator pode, de fato, ser considerado em qualquer sentido como anterior ao outro ${ }^{62}$. De forma geral, toda agência, seja direta ou indireta, é usada conjuntamente com uma quantidade indefinida de outras agências numa relação de cooperação de importância variada $^{63}$. Em cada instante de tempo, do ponto de vista econômico, tudo em existência que possua capacidade produtiva é, sem exceção, primário. Do ponto de vista histórico, tudo foi produzido no processo econômico como um todo, que se iniciou no princípio da história econômica ${ }^{64}$.

O pressuposto de Böhm-Bawerk e sua escola, de que os bens de capital são produzidos pelo trabalho ou por outros fatores que não o próprio capital, é absurdo ${ }^{65}$. A única distinção importante que se pode fazer entre os fatores de produção não é econômica, mas sim uma distinção "institucional" entre instrumentos produtivos comercializáveis (por conseguinte, sujeitos à contabilidade de capital) e não comercializáveis (e, portanto,

\footnotetext{
${ }^{62}$ KNIGHT, op. cit., 1933, p. 212.

${ }^{63}$ Idem. Ibidem., p. 215.

${ }^{64}$ KNIGHT, op. cit., 1935, p. 86.

${ }^{65}$ KNIGHT, op. cit., 1934, p. 262.
}

não sujeitos à contabilidade de capital ${ }^{66}$. Fica evidente que essa é uma distinção "institucional" pelo fato de que certos instrumentos que correntemente não são comercializáveis, já o foram historicamente. O exemplo óbvio é o próprio ser humano que, nos tempos da escravidão, era comercializado e, portanto, também era transformado em uma quantidade de capital por meio do processo de contabilidade de capital.

Na exposição formalizada de sua teoria, Hayek usa o termo "trabalho" (aspas no original) para designar um suposto fator original de produção homogêneo, sem se preocupar em discutir a questão da legitimidade dessa classificação ${ }^{67}$. Num artigo posterior, porém, Hayek rebate às críticas de Knight afirmando: primeiro, que as proposições concernentes à maior produtividade dos métodos indiretos de produção não dependem da possibilidade de identificar as contribuições de fatores originais remotos; segundo, e mais importante, que sua teoria não depende da distinção entre fatores originais (ou primários) e fatores produzidos ${ }^{68}$.

O motivo pelo qual Hayek diz que não é necessário determinar contribuições de fatores originais é que apenas os períodos futuros que separam o momento em que os fatores são ou serão investidos e o momento em que o produto amadurece são relevantes, e nunca os períodos passados que transcorreram desde o investimento de certos fatores originais. A teoria é ex ante, e não ex post; ela é forward-looking, e não backward-looking ${ }^{69}$.

Segundo Hayek, há duas formas de proceder à análise austríaca do capital sem fazer a distinção entre fatores originais e produzidos: 1) descrever o conjunto de períodos de investimento para todos os fatores existentes no início do período em questão, ou seja, tratar todos os fatores presentes como "origi-

\footnotetext{
${ }^{66}$ Idem. Ibidem., p. 264.

${ }^{67}$ HAYEK, op. cit., 1934, p. 209-10.

${ }^{68}$ HAYEK, op. cit., 1936, p. 208-9.

${ }^{69}$ Idem. Ibidem., p. 208.
} 
nais"; ou 2) apenas descrever o conjunto de períodos para os quais serviços de um tipo particular são investidos: serviços de fatores permanentes e que só se tornam disponíveis para novos investimentos em momentos sucessivos na medida em que são prestados ${ }^{70}$

Hayek favorece a segunda abordagem, a partir da qual se descreveria a função de investimento apenas do referido tipo de fatores permanentes. Nesse caso, substitui-se a distinção entre fatores originais e produzidos por uma nova distinção, a qual se baseia no fato de que alguns recursos produtivos devem ser deliberadamente substituídos, enquanto outros não requerem substituição sob bases econômicas. Pode-se aceitar ou não tal distinção, mas o fato é que a distinção tão criticada por Knight não é necessária para dar sentido à função de investimento ${ }^{71}$.

\section{3 - O fator tempo}

Talvez não exista forma melhor de sintetizar a controvérsia entre Hayek e Knight do que dizendo que se trata primordialmente de um debate sobre qual é o papel do fator tempo no processo produtivo. Para Hayek, o tempo é um fator essencial do processo produtivo. A ideia de roundaboutness - de métodos indiretos de produção ou de período de produção - é indispensável para a sua teoria dos ciclos a qual, por sua vez, é a fonte principal do interesse do autor pela teoria do capital. Knight, por outro lado, considera não só que a ideia de período de produção é dispensável, como também acredita que esse conceito é completamente desprovido de significado. Não surpreende, então, que critique duramente a teoria austríaca do capital, que colocaria uma ênfase completamente indevida num conceito irrelevante e sem significado.

\footnotetext{
${ }^{70}$ Idem. Ibidem., p. 208-9.

${ }^{71}$ Idem. Ibidem., p. 209.
}

\subsection{1 - O conceito de período de produção}

Em seu primeiro artigo da controvérsia, Knight argumenta que inexiste período de produção que possua duração ou significado determinados. Isso seria uma implicação lógica das duas perspectivas que podem ser adotadas na análise: as perspectivas estacionária e histórica ${ }^{72}$.

Pela perspectiva estacionária, todo o equipamento produtivo da sociedade rende serviços que são consumidos ao mesmo tempo em que são produzidos ${ }^{73}$. Para entender o que exatamente ele quer dizer com isso, vale a pena citar o exemplo do plantio de árvores dado por Stigler $^{74}$ em um trabalho que, inclusive, foi orientado por Knight. Se cinquenta árvores de um tipo qualquer demoram cinquenta anos para atingir a maturidade, haverá, no estado estacionário, um fluxo uniforme de cinquenta árvores maduras sendo cortadas e outro fluxo uniforme de cinquenta sementes de árvores sendo plantadas. Desse modo, dizer que cada árvore demora cinquenta anos para atingir a maturidade no estado estacionário é supérfluo e, nesse caso, a forma correta de enxergar o processo é considerar a produção e o consumo como sendo simultâneos. Em suma, numa economia estacionária, não há intervalo entre produção e consumo ${ }^{75}$

Do ponto de vista histórico, por outro lado, a criação do sistema produtivo como um todo foi um processo cumulativo e ininterrupto que se iniciou em tempos imemoriais e ao qual não pode ser atribuído nenhum fim definido, ao menos que fosse conhecido o dia do fim do mundo $^{76}$. A implicação disso é que se torna impossível associar um incremento de capacidade produtiva e um incremento de consumo, respectivamente, a intervalos finitos de rendimen-

\footnotetext{
72 Seriam essas as únicas perspectivas válidas? Knight, contrariamente a Hayek, acredita que sim. Ver mais na seção de metodologia e escopo da ciência econômica.

${ }^{73}$ KNIGHT, op. cit., 1933, p. 212.

${ }^{74}$ STIGLER, G. J. 1941. Production and Distribution Theories. New York, Macmillian. 1941.

${ }^{75}$ KNIGHT, op. cit., 1933, p. 223.

${ }^{76}$ Idem. Ibidem., p. 212, 223-24.
} 
tos e de atividade produtiva. A um incremento de atividade produtiva só pode ser associado um incremento no fluxo perpétuo de renda e a um incremento de consumo num intervalo de tempo só pode ser associado um fluxo interminável de atividade produtiva passada ${ }^{77,78}$.

Respondendo a Knight, Hayek implicitamente rejeita a dicotomia que o primeiro estabelece entre as perspectivas estacionária e histórica, afirmando que o valor principal da abordagem de "período de produção" reside justamente na análise de fenômenos dinâmicos ${ }^{79,80}$. Ao mesmo tempo em que afirma que é um erro interpretar o conceito de período de produção num sentido histórico ou ex post, Hayek faz uma crítica a autores que se limitam a analisar as implicações do estado estacionário. Em particular, a implicação criticada é a proposição de "sincronização" de Clark-Knight, a qual foi explicada através do exemplo das árvores e que esses autores acreditavam tornar irrelevante o conceito de período de produção. Hayek argumenta que, embora a sincronização deva necessariamente existir sob condições perfeitamente estacionárias, isso não quer dizer que algo na vida real irá, em algum momento, corresponder a isso. Ocorridas mudanças imprevistas após o investimento de capital em alguma forma particular, todo investimento posterior será influenciado por esse erro de previsão, de modo que o movimento para um equilíbrio estacionário será, na melhor das hipóteses, um movimento assintótico ${ }^{81}$.

Dado que a sincronização nunca existe de fato, também nunca existirá identidade

\footnotetext{
77 Idem. Ibidem., p. 224.

${ }^{78}$ Para Knight, só seria possível imputar um segmento de tempo de atividade produtiva a uma unidade de produto se não houver incremento de capacidade produtiva entre a produção e o consumo em questão (KNIGHT, op. cit, 1933, p. 224).

79 E essa afirmação não é nenhuma surpresa, dado que o desenvolvimento de sua teoria dinâmica dos ciclos econômicos era o objetivo principal de Hayek ao estudar a teoria do capital.

${ }^{80}$ Hayek, op. cit., 1934, p. 226.

${ }^{81}$ Idem. Ibidem., p. 226-27.
}

no sentido físico entre o estoque de produtos intermediários existentes em um instante e os produtos intermediários que estão sendo reproduzidos no mesmo instante através do investimento de fatores originais. Logo, os períodos de produção calculados ex ante e ex post serão duas grandezas distintas. Mas o que importam são os períodos para os quais estão sendo investidos os fatores de produção ofertados correntemente (período de produção ex ante) e nunca a duração do processo que resultou no produto corrente (período de produção ex post). Logo, a interpretação ex post do período de produção sempre levará a conclusões absurdas ${ }^{82}$.

Knight responde argumentando que aumentar a vida útil de um bem durável e estender o período de construção de um bem são apenas duas entre infinitas formas de aumentar a lucratividade de um empreendimento. Para ele, é um erro dar a designação de duração do processo produtivo a esses dois detalhes, os quais possuem tanta importância quanto infinitos outros, e tratar essa "duração do processo produtivo" como se fosse a única variável envolvida no cálculo racional do investimento ${ }^{83}$.

Além disso, Knight reafirma que o período de produção de serviços consumidos é zero e que o período de produção de todo o equipamento de capital da sociedade é toda a história humana passada ${ }^{84}$. No único sentido de temporalidade possível na análise econômica, a produção e o consumo são simultâneos. Não é possível nem dizer quando começou a ser produzido dado incremento de consumo, nem quando termina o consumo dos resultados de dado incremento na atividade produtiva ${ }^{85}$.

Respondendo à afirmação de Knight de que o tempo seria um mero detalhe entre infinitos outros e que a quantidade de capital poderia variar, independentemente de qualquer intervalo, Hayek afirma que todos os proble-

\footnotetext{
${ }^{82}$ Idem. Ibidem., p. 227.

${ }^{83}$ KNIGHT, op. cit., 1934, p. 268-70.

${ }^{84}$ KNIGHT, op. cit., 1935, p. 88.

${ }^{85}$ KNIGHT, op. cit., 1934 , p. 275-76.
} 
mas que são discutidos dentro do tema geral de "capital" emergem do fato de que parte do equipamento produtivo é não permanente e tem que ser deliberadamente substituída sob bases econômicas ${ }^{86}$. Logo, o tempo seria um fator essencial à discussão de capital.

Hayek também rejeita a concepção de produção de Knight, segundo a qual um homem que aplica seu trabalho na produção de um instrumento, o qual só contribuirá para a satisfação de um desejo no futuro, não produz o produto final que será obtido pela utilização do instrumento no futuro, mas produz um produto similar obtido no mesmo momento em que aplica seu trabalho e que é fruto da utilização de outro instrumento similar previamente existente. Para Hayek, uma concepção de "produção" que nos compele a dizer algo assim não passa de um "abuso absurdo de palavras" 87 .

Por fim, Hayek afirma ser inadmissível reduzir a descrição dos conjuntos de períodos pelos quais os diferentes fatores são investidos por uma expressão de dimensão temporal única como o período médio de produção. Segundo Hayek, Knight estaria errado em achar que expor as ambiguidades e inconsistências envolvidas na noção de período médio de investimento justificaria o expurgo completo da ideia de tempo da teoria do capital. Em alguns casos simples, há inequivocamente um aumento da dimensão temporal do investimento (por exemplo, quando o período de investimento de alguns fatores aumenta, enquanto os períodos de todos os outros permanecem constantes). Em outros casos mais complicados, é impossível determinar imediatamente se a estrutura de investimento foi alongada ou encurtada ${ }^{88}$. Para tanto, seria necessário comparar dois agregados de espera calculados da seguinte forma:

In consequence the only way in which an aggregate of waiting can be described, and

\footnotetext{
${ }^{86}$ KNIGHT, op. cit., 1936, p. 494.

${ }^{87}$ Idem. Ibidem., p. 506.

${ }^{88}$ Idem. Ibidem., p. 497.
}

the amount of waiting involved in different investment structures can be compared, is by means of a process of summation, in the form of a double integral over the function describing the rates, at which the factors that contribute to the product of any moment are applied, and at which interest accrues ${ }^{89}$.

\subsection{2 - Mais capital equivale a processos produti- vos mais longos?}

Ao longo de seus artigos, Knight confronta a proposição austríaca de que a acumulação de capital levaria a um aumento da dimensão temporal do processo produtivo (ou seja, do período de produção). Segundo ele, em nenhum sentido o uso de mais capital na produção pode ser interpretado como significando um processo produtivo mais longo. Knight reconhece que a criação de capital não pode ocorrer instantaneamente, mas também afirma que não existe nenhuma conexão necessária entre a quantidade de capital e o tempo necessário para construí-lo. Desse modo, qualquer quantidade de capital pode ser criada em qualquer período de tempo $^{90}$. Novos investimentos podem não envolver nem um aumento na durabilidade média dos bens envolvidos, nem um aumento do período de construção desses bens.

Como já visto, para Hayek, a condição de equilíbrio da estrutura de capital no caso de bens em processo é que os produtos marginais do fator "original" se igualem em valor, ou seja, que os produtos marginais de cada unidade, descontados pelos respectivos períodos que são investidos, se igualem. Se a taxa de juros diminui (ou a oferta de capital livre aumenta), ocorre um aumento do valor dos fatores investidos nos estágios mais iniciais relativamente aos estágios mais adiantados de produção. Isso, por sua vez, provoca uma tendência de realocação de fatores de produção dos estágios mais adiantados para os estágios mais iniciais. Ocorre, portanto,

\footnotetext{
${ }^{89}$ Idem. Ibidem., p. 497.

${ }^{90}$ KNIGHT, op. cit., 1933, p. 225.
} 
um alongamento da estrutura de produção ${ }^{91}$.

O caso de bens duráveis é análogo ao de bens em processo. Se a taxa de juros diminui (ou a oferta de capital livre aumenta), então aumenta o valor presente dos serviços mais distantes desses bens relativamente ao valor dos serviços menos distantes. Desse modo, aumenta o valor dos fatores originais investidos na produção de bens mais duráveis relativamente aos investidos na produção de bens menos duráveis. Há, então, uma realocação de fatores, de modo que mais bens duráveis (ou, quando possível, bens mais duráveis) sejam produzidos ${ }^{92}$.

Para obter esses resultados não é, no entanto, necessário que haja alongamento da estrutura de produção de nenhuma indústria em particular. Se as funções de investimentos de todas as indústrias forem completamente rígidas, então um aumento na o zferta de capital livre levará a um aumento do produto das indústrias de estruturas produtivas mais longas em detrimento daquelas de estruturas produtivas mais curtas. Assim, a função de investimento da economia alonga-se sem que se alongue a função de investimento de nenhuma indústria em particular ${ }^{93}$.

Num artigo posterior, Knight interpreta como uma rendição a afirmação de Hayek de que mais bens duráveis (ou, quando possível, bens mais duráveis) seriam produzidos devido a uma diminuição da taxa de juros. Mais bens do mesmo tipo, segundo Knight, não implicariam em nenhuma mudança nem na função de investimento, nem na função de produto, do modo como foram definidas por Hayek e, portanto, não haveria nenhum alongamento da estrutura temporal de investimento. Por isso, Hayek teria implicitamente reconhecido que mais capital não implica necessariamente em processos produtivos mais longos ${ }^{94}$.

\footnotetext{
${ }^{91}$ KNIGHT, op. cit., 1934, p. 222.

${ }^{92}$ Idem. Ibidem., p. 224-25.

${ }^{93}$ Idem. Ibidem., p. 223.

${ }^{94}$ KNIGHT, op. cit., 1935, p. 77-78.
}

Knight, então, elabora um exemplo relacionado ao plantio agrícola para demonstrar que a quantidade de capital não tem nenhuma relação simples e definida com qualquer intervalo de tempo. Argumenta:

Taking population as given, raising more plants of the same growth period will also require more "stock", but will not affect the length of the cycle, while the addition to total production of new varieties of shorter growth, say yielding two harvests per year instead of one, will involve an increase in the capital, while shortening the average cycle. [...] In the third case, which is intrinsically as probable as the other two, production may be maintained with a shortened cycle, and capital released or production increased and the same amount of capital used ${ }^{95}$.

É verdade, argumenta Knight, que em todos os três casos, necessita-se de tempo para realizar a transição de um estado para outro. Mas esse tempo não deve ser confundido com o tempo de duração do ciclo de produção em si, confusão esta cometida pela teoria austríaca. Por fim, Knight argumenta que somente existe correspondência entre a quantidade de capital e o tempo se for pressuposto que o capital é depreciado a uma taxa constante:

"It is only under the arbitrary and absurd assumption that capital is eaten up at a fixed rate (such as the fixed scale of support for labour) that there is any correspondence between a quantity of capital and the length of a productive cycle $\mathrm{e}^{\prime 96}$.

Em resposta, Hayek afirma que "um aumento do capital irá sempre significar uma extensão da dimensão temporal do investimento" (ênfase de Hayek) e que um aumento do produto que possua como pré-requisito um acréscimo do capital só ocorrerá se, simultaneamente, houver um aumento da dimensão temporal do investimento ${ }^{97}$.

\footnotetext{
${ }^{95}$ Idem. Ibidem., p. 81.

${ }^{96}$ Idem. Ibidem., p. 82.

${ }^{97}$ HAYEK, op. cit., 1936, p. 494
} 
Defendendo-se da acusação de que ele teria "se rendido" na sua discussão de bens duráveis e implicitamente aceitado que mais capital não implica necessariamente em um alongamento da estrutura temporal de produção, Hayek diz que Knight interpretou sua frase de maneira equivocada. Quando ele disse que "mais bens (ou, quando possível, bens mais duráveis) do mesmo tipo serão produzidos", o tipo de bens ao qual se referia era o de bens relativamente mais duráveis ${ }^{98}$. Parafraseando, o que realmente quis dizer foi que, em decorrência de uma diminuição da taxa de juros, "mais bens (ou, quando possível, bens de durabilidade ainda maior do que a dos previamente existentes) relativamente mais duráveis serão produzidos". De fato, isso é compatível com a discussão que antecedeu a frase original ${ }^{99}$, mostrando que não houve "rendição" alguma.

Em relação ao exemplo da plantação, Hayek aponta que Knight não teria explicitado a razão pela qual os novos métodos de plantio só se tornariam possíveis com um aumento da oferta de capital. Para Hayek, supondo constantes a população (pressuposto do exemplo de Knight) e o conhecimento técnico (pressuposto da teoria austríaca), só parece haver uma possibilidade para que o novo método seja dependente do aumento da oferta de capital: o novo capital deve ser usado para comprar instrumentos, máquinas, etc. que serão feitos por pessoas que anteriormente estavam diretamente empregadas no plantio ${ }^{100}$. Logo, o exemplo de Knight não refutaria a tese austríaca de que mais capital implica em processos produtivos mais tempo-intensivos e, acrescenta Hayek, tal exemplo seria a única passagem do artigo de Knight em que ele tenta demonstrar a falsidade dessa tese ${ }^{101}$.

\footnotetext{
${ }^{98}$ Idem. Ibidem., p. 504-05.

${ }^{99}$ HAYEK, op. cit., 1934, p. 224-25.

${ }^{100}$ HAYEK, op. cit., 1936, p. 502.

${ }^{101}$ Idem. Ibidem., p. 504.
}

3.4 - Método e escopo da ciência econômica: implicações na controvérsia

Alguns intérpretes da controvérsia entre Hayek e Knight ${ }^{102}$ argumentam que a divergência entre ambos os autores sobre a teoria do capital provém, em grande parte, de suas posições metodológicas e da visão que cada um deles possuía em relação aos limites da teoria econômica.

Para Knight, a economia não seria uma ciência empírica no sentido estrito da palavra, pois seus axiomas e conclusões não podem ser conhecidos por observação e não podem ser verificados. Os princípios gerais da teoria econômica seriam conhecidos a priori como fatos e decorrem dos próprios termos "economia" e "economizar": atingir o "máximo" entre alguns fins gerais utilizando dados meios (ou a maximização da utilidade sujeita a restrições, usando termos mais familiares). Todos nós saberíamos, por exemplo, que as pessoas utilizam meios para alcançar fins, que o uso de meios é tipicamente indireto para produzir bens e serviços (que são os meios diretos de satisfação de desejos), etc. Mas esses princípios gerais, ao mesmo tempo em que são "axiomáticos" quando explicitados, levantam uma série de questões e precisam ser defendidos e elucidados ${ }^{103}$.

Desse modo, a economia seria um exercício de abstração e análise: ela cria a abstração de um reino que isola certos aspectos da

${ }^{102}$ Cf. EMMETT, R. B. "What Is Truth" in Capital Theory? Five Stories Relevant to the Evaluation of Frank H. Knight's Contribution to the Capital Controversy. In New Economics and Its History, edited by J. B. Davis. HOPE 29 (supplement): 231-50. 1998. BOETTKE, P. VAUGHN, K. Knight and the Austrians on Capital, and the Problem of Socialism. History of Political Economy, Vol. 34, No. 1 (2002): 155-76. COHEN, A. J. The Hayek/Knight Capital Controversy: The Irrelevance of Roundaboutness, or Purging Processes in Time? History of Political Economy, Vol. 35, No. 3 (Fall 2003): 469-90.

103 KNIGHT, F. Methodology in Economics: Part I. Southern Economic Journal, Vol. 27, No. 3 (1962): 18593. Cit. p. 187-88. 
realidade, reino esse que permite que tais aspectos sejam analisados em termos de seus impactos individuais e de suas interações entre si. Uma disciplina científica de abstração e análise buscaria a verdade, entendida não em termos empíricos, mas em termos "definicionais". Uma "boa" teoria seria como uma boa definição; seria uma teoria desprovida de elementos que "poluiriam" a análise, ou seja, uma teoria que corretamente captura o significado do aspecto particular da experiência humana em consideração ${ }^{104}$.

Reflexos dessa posição metodológica de Knight são facilmente percebidos em sua teoria do capital e também nos ataques que faz à teoria austríaca. Ao longo dos artigos da controvérsia, seus argumentos são feitos através de definições de termos como consumo, produção, riqueza, etc. e, muitas vezes, aqueles se confundem com essas ${ }^{105}$. Sua teoria do capital é consequência do que, para ele, seriam as definições corretas das categorias envolvidas. A teoria austríaca, por outro lado, envolveria "confusões fatais" e, como consequência, constituiria uma visão falsa da natureza da cooperação entre o trabalho e o capital ${ }^{106}$. Os austríacos, para Knight, usariam certos ermos de forma imprecisa. Exemplo disso seria o termo "produção", que os austríacos utilizam no sentido de produção de riqueza, mas cujo sentido correto seria produção de serviços:

The chief center of confusion in the treatment of economic concepts, particularly as regards the time dimension, is the notion of production. [...] The fundamental confusion is that between production as the rendering of consumption service (at some rate) and the creation of some (absolute quantity of) new capacity to render such

${ }^{104}$ EMMETT, op. cit.

${ }^{105}$ Vale ressaltar que uma das maiores dificuldades na compreensão dos artigos de Knightjaz na familiarização com os termos utilizados pelo autor, algumas vezes usados de forma bastante idiossincrática pelo mesmo.

${ }^{106}$ KNIGHT, op. cit., 1933, p. 211-2. service $^{107}$.

Outros conceitos utilizados na teoria austríaca não possuiriam sequer significado definido e, portanto, seu uso deveria ser interrompido. Esse seria o caso de "período de produção" ou "duração do processo produtivo", pois seria impossível dizer quando se inicia a produção de dado incremento de consumo e quando termina o consumo de dado incremento de atividade produtiva ${ }^{108}$.

Dada essa equalização de teorização com definição, também não surpreende que haja uma grande dose de repetição nos artigos de Knight. Seu objetivo com isso, como dito na frase citada de Spencer, é de "forçar conceitos estranhos sobre mentes relutantes". Isso ressoa com uma observação que o próprio Knight faz posteriormente de que uma das maiores dificuldades do economista é que sua tarefa seria, em grande parte, a de ensinar às pessoas coisas que elas já saberiam ${ }^{109}$. Através da repetição variada de definições, Knight buscava fazer com que seus interlocutores se dessem conta que já sabiam que a teoria do capital de Knight era a verdadeira.

É difícil determinar qual era a posição metodológica exata de Hayek no período de sua controvérsia com Knight, pois seus escritos sobre metodologia foram feitos posteriormente. No entanto, em depoimentos autobiográficos, o autor afirma que: (1) nunca havia aceitado o apriorismo metodológico como, por exemplo, aquele defendido por seu antigo mentor, Mises; (2) era um defensor intuitivo do falsificacionismo popperiano antes

\footnotetext{
${ }^{107}$ Idem. Ibidem., p. 216-7, ênfase do autor.

${ }^{108}$ KNIGHT, op. cit., 1934, p. 275.

${ }^{109}$ KNIGHT, op. cit., 1961, p. 187.
} 
de sua leitura dos trabalhos de Popper, com os quais se identificara ${ }^{110,111}$.

Outra divergência entre Hayek e Knight, que tem implicações na controvérsia entre ambos, é em relação ao escopo da ciência econômica. Para Hayek, processos econômicos que ocorrem fora do equilíbrio podem ser legitimamente analisados pela economia. Knight, por outro lado, acreditava que a teoria econômica apenas lidaria com as consequências do comportamento maximizador (sujeito a restrições) sob condições de certeza atemporal ${ }^{112}$.

Knight defendia que haveria uma dicotomia entre as abstrações da teoria econômica e o estudo da evolução histórica da estrutura institucional da sociedade. Para Knight, o método da abstração e análise, por pressupor a ausência de incerteza, seria inadequado para analisar condições dinâmicas do mundo real, nas quais a incerteza impera. Segundo ele, seria necessário desenvolver um novo tipo de institucionalismo para lidar com as mudanças históricas, as quais a economia tomava como dados ${ }^{113}$.

Essa dicotomia entre o reino da teoria econômica e o reino histórico-institucional encontra correspondência, dentro do contexto da controvérsia, na já referida dicotomia que Knight estabelece entre as perspectivas estacionária e histórica, quando critica o conceito de período de produção ${ }^{114}$. Na perspectiva estacionária (reino da

\footnotetext{
${ }^{110}$ HAYEK, F. A. Hayek on Hayek: An Autobiographical Diologue. University of Chicago Press. 1994.
}

111 Há controvérsia a respeito da real influência de Popper sobre Hayek e vice-versa. C.f. CALDWELL, B. Popper and Hayek: Who influenced whom? In: Karl Popper: A Centenary of Assessment. Vol. 1. Aldershot, Ashgate. 2006.

112 BOETTKE \& VAUGHN, op. cit., p. 158.

${ }^{113}$ EMMETT, op. cit., 1998.

${ }^{114} \mathrm{O}$ escopo delimitado por Knight à teoria econômica também se reflete na sua afirmação de que o capital é perpétuo: "Capital is perpetual in so far as economic principles obtain and economic reasoning is applicable" (KNIGHT, op. cit., 1934, p. 277). teoria econômica), a produção e o consumo deveriam ser considerados simultâneos ${ }^{115}$. Pela perspectiva histórica (reino histórico-institucional), o período de produção de todo o equipamento de capital da sociedade seria toda história humana passada ${ }^{116}$. No seguinte trecho, essa dicotomia fica bem clara:

If production is regarded as a process occupying time, its only beginning is the beginning of time, and its only end is the end of time - or, we might say, the beginning and end of social economic life. In the only sense of timing in terms of which economic analysis is possible, production and consumption are simultaneous ${ }^{117}$.

Para Knight, portanto, o que os teóricos austríacos do capital desejavam fazer - analisar processos no tempo em termos teóricos - era simplesmente inadmissível. Processos no tempo, segundo ele, só poderiam ser analisados em termos histórico-institucionais. Não haveria sentido econômico em dizer que existe correspondência entre o capital e algum período de tempo pelo simples fato de que, sob condições de certeza atemporal, nenhum intervalo de tempo poderia possuir qualquer relevância.

Em contraste com essa posição, Hayek defendia que a importância principal da abordagem de período de produção residia justamente na análise de processos dinâmicos. Hayek concorda que a proposição de "sincronização", que está na base da afirmação de Knight de que produção e consumo são simultâneos, seria de fato verdadeira sob condições estacionárias. Isso, porém, não justificaria o descarte da abordagem de período de produção, pois as condições estacionárias nunca seriam verificadas no mundo real. Para Hayek, limitar-se à análise das implicações do estado estacionário seria, portanto, um erro,

\footnotetext{
${ }^{115}$ KNIGHT, op. cit., 1933, p. 223.

${ }^{116}$ KNIGHT, op. cit., 1935, p. 88.

${ }^{117}$ KNIGHT, op. cit., 1934, p. 275.
} 
uma vez que mudanças imprevistas sempre impedem a chegada a tal estado ${ }^{118}$.

As divergências entre Hayek e Knight a respeito do escopo da economia constituíam, portanto, um grande entrave à possibilidade de chegarem a algum acordo sobre a teoria do capital. Knight não podia aceitar a teoria austríaca do capital, a qual violava sua dicotomia entre economia e história. Hayek, por outro lado, cujo interesse central no estudo da teoria do capital era fundamentar melhor sua teoria dinâmica dos ciclos, não aceitaria a remoção da análise de processos no tempo do escopo da economia. De fato, em entrevista posterior, Hayek demonstra ter sentido que a controvérsia com Knight nunca resultaria em convergência de posições:

Buchanan: What were your relationships with Frank Knight?

Hayek: Personally, very good. We had several very friendly controversies. I think we were always more puzzled by each other than anything else. It was not a real meeting of minds. With great effort, you know, we had some serious discussion, but somehow we were talking mostly at cross-purposes. Buchanan: Certainly on capital theory. [laughter] ... he spent [years] attacking the Austrians, essentially.
Hayek: He was frightfully dogmatic about it. He asserted that he was absolutely certain, and he had very few arguments to justify it. I always assumed it must have been some very early teaching which he had absorbed and to which he had stuck; he hadn't done any further thinking about it, but felt that it was one of the foundations of his economics, to which he had to stick. ${ }^{119}$

Hayek tinha certa razão - Knight não poderia abandonar sua teoria do capital sem abandonar também uma das bases de sua economia, quer seja, a própria delimitação do escopo da ciência econômica. Mas algo similar poderia ser dito de Hayek: não poderia abandonar sua teoria do capital sem também abandonar sua teoria dos ciclos ${ }^{120}$, a qual dependia fundamentalmente de sua teoria do capital e que, apesar de não poder ser considerada uma das bases da economia de Hayek, constituiu um de seus objetos centrais de interesse e estudo durante vários anos. A convergência dos dois autores a respeito da teoria do capital exigiria, portanto, que pelo menos um deles revisasse posições sensíveis, o que tornava pouco viável a ocorrência de algum tipo de acordo entre ambos. cos
119 HAYEK, F. A. Interview with Friedrich Hayek by James Buchanan. Pacific Academic Advanced Studies. Disponível em: < http://hayek.ufm.edu/index. php?title=James_Buchanan $>$. 1978.

${ }^{120}$ HAYEK, F. A. Prices and Production. 2d ed. London: Routledge. 1935. 